\title{
On the frequency of $\mathrm{N}_{2} \mathrm{H}^{+}$and $\mathrm{N}_{2} \mathrm{D}^{+\star}$ (Research Note)
}

\author{
L. Pagani ${ }^{1}$, F. Daniel ${ }^{1,2}$, and M.-L. Dubernet ${ }^{1}$ \\ 1 LERMA \& UMR8112 du CNRS, Observatoire de Paris, 61 Av. de l'Observatoire, 75014 Paris, France \\ e-mail: [laurent.pagani; marie-lise. dubernet]@obspm. fr \\ 2 Department of Molecular and Infrared Astrophysics (DAMIR), Consejo Superior de Investigaciones Científicas (CSIC), \\ C/ Serrano 121, 28006 Madrid, Spain \\ e-mail: daniel@damir.iem.csic.es
}

Received 11 July 2008 / Accepted 10 November 2008

\section{ABSTRACT}

\begin{abstract}
Context. Dynamical studies of prestellar cores search for small velocity differences between different tracers. The highest radiation frequency precision is therefore required for each of these species.

Aims. We want to adjust the frequency of the first three rotational transitions of $\mathrm{N}_{2} \mathrm{H}^{+}$and $\mathrm{N}_{2} \mathrm{D}^{+}$and extrapolate to the next three transitions.

Methods. We compare $\mathrm{N}_{2} \mathrm{H}^{+}$and $\mathrm{N}_{2} \mathrm{D}^{+}$to $\mathrm{NH}_{3}$, the frequency of which is more accurately known and which has the advantage of being spatially coexistent with $\mathrm{N}_{2} \mathrm{H}^{+}$and $\mathrm{N}_{2} \mathrm{D}^{+}$in dark cloud cores. With lines among the narrowest, and the $\mathrm{N}_{2} \mathrm{H}^{+}$and $\mathrm{NH}_{3}$ emitting region among the largest, $\mathrm{L} 183$ is a good candidate for comparing these species.

Results. A correction of $\sim 10 \mathrm{kHz}$ for the $\mathrm{N}_{2} \mathrm{H}^{+}(J: 1-0)$ transition is found $\left(\sim 0.03 \mathrm{~km} \mathrm{~s}^{-1}\right)$. Similar corrections from a few m s up to $\sim 0.05 \mathrm{~km} \mathrm{~s}^{-1}$ compared to previous astronomical determinations are reported for the other transitions $\left(\mathrm{N}_{2} \mathrm{H}^{+}(J: 3-2)\right.$ and $\mathrm{N}_{2} \mathrm{D}^{+}(J: 1-0),(J: 2-1)$, and $\left.(J: 3-2)\right)$. Einstein spontaneous-decay coefficients $\left(A_{u l}\right)$ are included.
\end{abstract}

Key words. molecular data - ISM: kinematics and dynamics - radio lines: ISM

\section{Introduction}

In the quest for star-forming cores, kinematic studies play a crucial role by trying to unveil either the slowly contracting cores or the fast collapsing ones, depending upon which theory we rely upon or at what moment along the evolutionary track the prestellar core is standing. As already discussed by Lee et al. (1999), accurate knowledge of every species' line frequency is of utmost importance in tracking small systematic velocity gradients in molecular clouds. Because these velocity shifts can be as small as a few tens of $\mathrm{m} \mathrm{s}^{-1}$, millimeter line transitions should be known with a precision of at least $10^{-7}$ and ideally $10^{-8}$. Some species are easily measured in the laboratory, especially stable species like $\mathrm{CO}, \mathrm{NH}_{3}$, etc. Others are unstable and more difficult to measure (such as $\mathrm{OH}, \mathrm{H}_{2} \mathrm{D}^{+}$, etc.). One possibility in the latter case is to compare the transitions of those species with the transitions of another well-known species in dark cloud cores where the lines are narrow enough to be accurately measured. However, the obvious difficulty is to be sure that the two species share the same volume in the cloud and undergo the same macroscopic velocity shifts. Even so, the line opacities might be a problem if too different in presence of a velocity gradient causing the two coexistent species to then emphasize different parts

* Based on observations made with the IRAM 30-m and the GBT 100m. IRAM is supported by INSU/CNRS (France), MPG (Germany), and IGN (Spain). GBT is run by the National Radio Astronomy Observatory, which is a facility of the National Science Foundation operated under cooperative agreement by Associated Universities, Inc. of the cloud, depending on the depth at which their respective opacity reaches 1 . A problem of opacity was indeed met in the comparison of CS with CCS made by Kuiper et al. (1996) in their attempt to measure the frequency of the CS lines, as discussed in Pagani et al. (2001).

Caselli et al. (1995) performed such a measurement for $\mathrm{N}_{2} \mathrm{H}^{+}$, comparing $\mathrm{N}_{2} \mathrm{H}^{+}(\mathrm{J}: 1-0)$ line emission to the $\mathrm{C}_{3} \mathrm{H}_{2}$ $\left(J_{\mathrm{KK}^{\prime}}: 2_{12}-1_{01}\right)$ line emission in L1512, confirming a sizeable difference between laboratory measurements and astronomical observations. Expanding on a previous work by Gerin et al. (2001), Dore et al. (2004) also calculated and observed the $\mathrm{N}_{2} \mathrm{D}^{+}$ $(J: 1-0)$ transition in L183, and extrapolated to the higher $\mathrm{N}_{2} \mathrm{D}^{+}$ transitions (giving slightly different values compared to Gerin et al. 2001, for the $J: 2-1$ and $J: 3-2$ transitions). They aligned their $\mathrm{N}_{2} \mathrm{D}^{+}(J: 1-0)$ observation onto their $\mathrm{N}_{2} \mathrm{H}^{+}(J: 1-0)$ towards the same source with the same telescope. The $\mathrm{N}_{2} \mathrm{H}^{+}$rotational constant was itself redetermined from a new evaluation of the $\mathrm{N}_{2} \mathrm{H}^{+}(J: 1-0)$ frequency, itself from a comparison with $\mathrm{C}^{18} \mathrm{O}(\mathrm{J}: 1-0)$ in the L1512 cloud (see Dore et al. 2004, for more details). This new value gave an offset of $-4.2 \mathrm{kHz}$ from their previous determination.

While the direct comparison of the $\mathrm{N}_{2} \mathrm{D}^{+}$and $\mathrm{N}_{2} \mathrm{H}^{+}$lines is presently the best option because $\mathrm{N}_{2} \mathrm{H}^{+}$must exist where $\mathrm{N}_{2} \mathrm{D}^{+}$ exists, the hypothesis that $\mathrm{C}_{3} \mathrm{H}_{2}$ is also present in the same volume as $\mathrm{N}_{2} \mathrm{H}^{+}$is more questionable because of differential depletion problems. Dore et al. (2004) also note that using $\mathrm{C}^{18} \mathrm{O}$ has the problem of tracing different regions but, hoped for a null velocity shift between the two tracers. We think that a better 
possibility exists for accurately measuring the frequency of $\mathrm{N}_{2} \mathrm{H}^{+}$, namely by taking $\mathrm{NH}_{3}$ as the frequency reference. It is clear that $\mathrm{NH}_{3}$ and $\mathrm{N}_{2} \mathrm{H}^{+}$are coexistent species in depleted prestellar cores (e.g. Tafalla et al. 2002, 2004), because they have a common chemical origin and show similar extents in most cores.

In this Note, we present a detailed comparison of $\mathrm{NH}_{3}$ with $\mathrm{N}_{2} \mathrm{H}^{+}$and $\mathrm{N}_{2} \mathrm{D}^{+}$in L183, checking that the measurable velocity shifts across the core are the same for all three species, to convince ourselves of their coexistence and the absence of any opacity effect on the velocity peak position. Schmid-Burgk et al. (2004) have developed a similar strategy in their study of the $\mathrm{H}^{13} \mathrm{CO}^{+}$and ${ }^{13} \mathrm{CO}$ hyperfine structure (hereafter HFS) towards another dark cloud, L1512, with similar very narrow linewidths. With these comparisons in hand, we give all corrections for the 5 most currently observed transitions, together with their Einstein spontaneous decay coefficients $\left(A_{u l}\right)$, determine the best-fitting rotational constants and compute the expected frequencies for the next 3 rotational transitions $(J: 4-3$, $5-4,6-5)$.

\section{Observations}

The whole elongated dense core of L183 (reference position: $\alpha_{2000}=15^{\mathrm{h}} 54^{\mathrm{m}} 08.5^{\mathrm{s}} \delta_{2000}=-2^{\circ} 52^{\prime} 48^{\prime \prime}$ ) has now been fully mapped wih the IRAM $30-\mathrm{m}$ telescope in a series of observations spanning several years from November 2003 to July 2007. The $\mathrm{N}_{2} \mathrm{H}^{+}$and $\mathrm{N}_{2} \mathrm{D}^{+}(J: 1-0)$ lines were fully mapped, while the $\mathrm{N}_{2} \mathrm{H}^{+}(J: 3-2), \mathrm{N}_{2} \mathrm{D}^{+}(J: 2-1)$ and $(J: 3-2)$ lines were mapped mostly towards the main core and its elongated ridge and partly towards the peak of the northern core (see Pagani et al. 2004, 2005). All observations were performed in frequencyswitch mode. For the $(J: 1-0)$ lines, the frequency sampling is $10 \mathrm{kHz}, 10$, or $20 \mathrm{kHz}$ for the $(J: 2-1)$ and $40 \mathrm{kHz}$ for the $(J: 3-2)$ lines, providing comparable velocity resolution for all lines in the range $30-50 \mathrm{~m} \mathrm{~s}^{-1}$. Spatial resolution ranges from $33^{\prime \prime}$ at $77 \mathrm{GHz}$ to $9^{\prime \prime}$ at $279 \mathrm{GHz}$. For all lines, the spatial sampling is $12^{\prime \prime}$ for the main prestellar core and $15^{\prime \prime}$ for the southern extension and for the northern prestellar core. We used Caselli et al. (1995) and Dore et al. (2004) frequencies for $\mathrm{N}_{2} \mathrm{H}^{+}$and $\mathrm{N}_{2} \mathrm{D}^{+}$transitions, respectively.

We observed $\mathrm{NH}_{3}(1,1)$ and $(2,2)$ inversion lines towards the whole core at the new Green Bank 100-m telescope (GBT) in November 2006 and March 2007, with velocity sampling of $20 \mathrm{~m} \mathrm{~s}^{-1}$ and a typical $T_{\text {sys }}$ of $50 \mathrm{~K}$, in frequency-switch mode. The angular resolution $\left(\sim 35^{\prime \prime}\right)$ is close to that of the $30-\mathrm{m}$ for the low-frequency $(J: 1-0) \mathrm{N}_{2} \mathrm{D}^{+}$line. The spatial sampling is $24^{\prime \prime}$ all over the source. We used the accurate measurement of Kukolich (1967) for $\mathrm{NH}_{3}(1,1)$, namely $v=$ $23694495487( \pm 48) \mathrm{Hz}$, which is an average estimated from the whole HFS (see also Hougen 1972, who revisited the $\mathrm{NH}_{3}$ and ${ }^{15} \mathrm{NH}_{3}$ frequencies. The reported accuracy is higher but the $\mathrm{NH}_{3}(1,1)$ frequency remains basically unchanged, namely $v=$ $23694495481 \pm 22 \mathrm{~Hz}$ ). For this frequency, the two strongest hyperfine components have the following frequency offsets:

$\Delta v\left(F_{1} F: 2,{ }^{5} / 2 \rightarrow 2,{ }^{5} / 2\right)=10463 \mathrm{~Hz}$

$\Delta v\left(F_{1} F: 2,{ }^{3} / 2 \rightarrow 2,{ }^{3} / 2\right)=-15196 \mathrm{~Hz}$.

Samples of these spectra $\left(\mathrm{N}_{2} \mathrm{H}^{+}, \mathrm{N}_{2} \mathrm{D}^{+}\right.$and $\left.\mathrm{NH}_{3}\right)$ are displayed in Pagani et al. (2007).

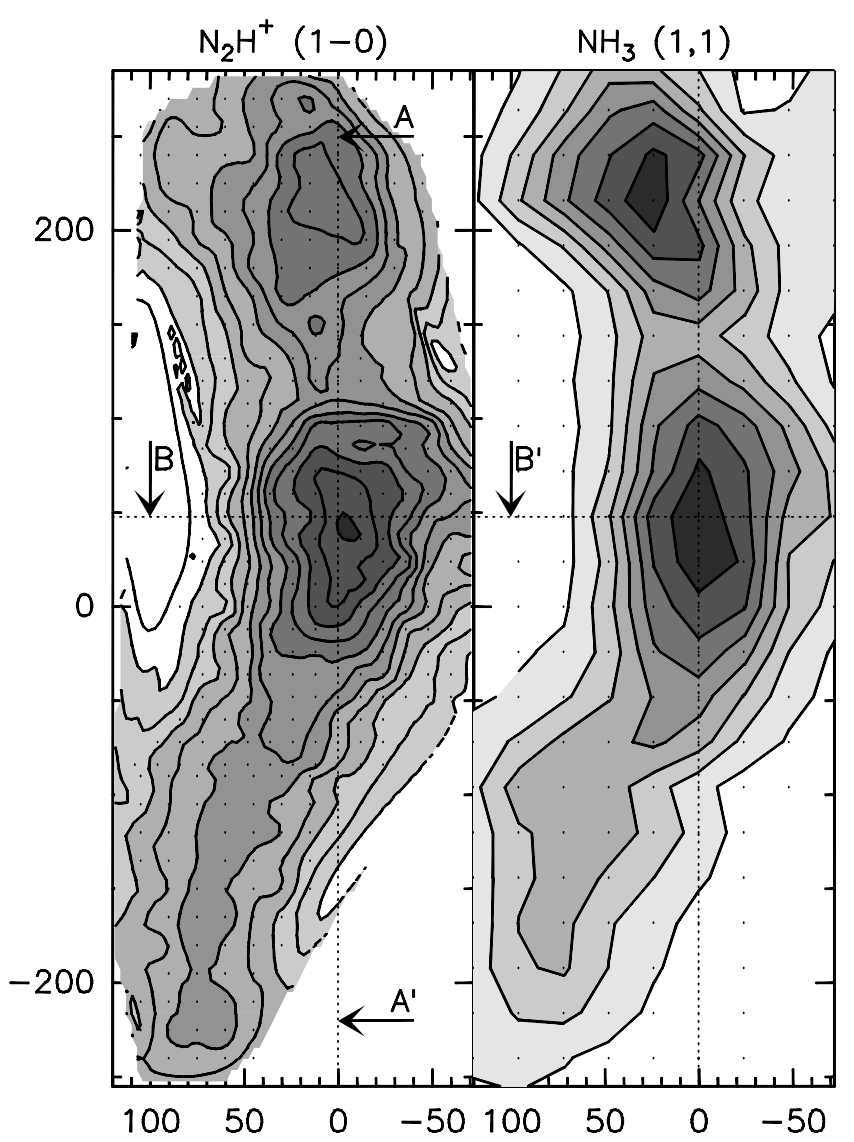

Fig. 1. $\mathrm{N}_{2} \mathrm{H}^{+}\left(J\right.$ : 1-0) (left) and $\mathrm{NH}_{3}(1,1)$ (right) integrated intensity maps. The dotted lines $\mathrm{AA}^{\prime}$ and $\mathrm{BB}^{\prime}$ indicate the profiles along which the velocity gradients are traced in Figs. 2 and 3. Reference position: $\alpha_{2000}=15^{\mathrm{h}} 54^{\mathrm{m}} 08.5^{\mathrm{s}} \delta_{2000}=-2^{\circ} 52^{\prime} 48^{\prime \prime}$.

\section{Spatial coexistence of ammonia and diazenylium}

Though depletion of molecules was predicted in the 70s, it was only a few years after the publication of the Caselli et al. (1995) paper on the frequency of $\mathrm{N}_{2} \mathrm{H}^{+}$that depletion was actually discovered and traced (e.g. Willacy et al. 1998). Therefore the hypothesis made by Caselli et al. (1995) that $\mathrm{C}_{3} \mathrm{H}_{2}$ and $\mathrm{N}_{2} \mathrm{H}^{+}$ are spatially coexistent is probably refutable, because it is clear now that such a heavy carbon carrier should be depleted in the same region as $\mathrm{CO}$, which is the region where $\mathrm{N}_{2} \mathrm{H}^{+}$appears. Indeed, the detection of $\mathrm{N}_{2} \mathrm{D}^{+}$in L1512 as a large fraction of $\mathrm{N}_{2} \mathrm{H}^{+}$(Roberts \& Millar 2007) is a clear sign of heavy depletion of other molecules. Therefore the velocity coincidence between these two species is questionable.

Ammonia and diazenylium have the same chemical origin, starting from $\mathrm{N}_{2}$ and are well-known to be coexistent, as discussed by e.g. Tafalla et al. (2002, 2004). This is particularly true in L183 as can be seen in Fig. 1 (but not for $\mathrm{C}_{3} \mathrm{H}_{2}$ which is much less extented, mostly concentrated towards the northern prestellar core, as can be seen in Swade 1989). Interestingly, the velocity along the dense filament is constantly changing (Fig. 2), evoking a flow towards the prestellar cores, and the cut perpendicular to the filament (marked $\mathrm{BB}^{\prime}$ in Fig. 1) suggests a rotation of the filament around its vertical axis (Fig. 3). The $\mathrm{NH}_{3}(1,1)$, $\mathrm{N}_{2} \mathrm{H}^{+}$and $\mathrm{N}_{2} \mathrm{D}^{+}(\mathrm{J}: 1-0)$ lines all trace exactly the same gradients so it seems compulsory that the velocities of the different compounds be identical, as there is no obvious possibility that 


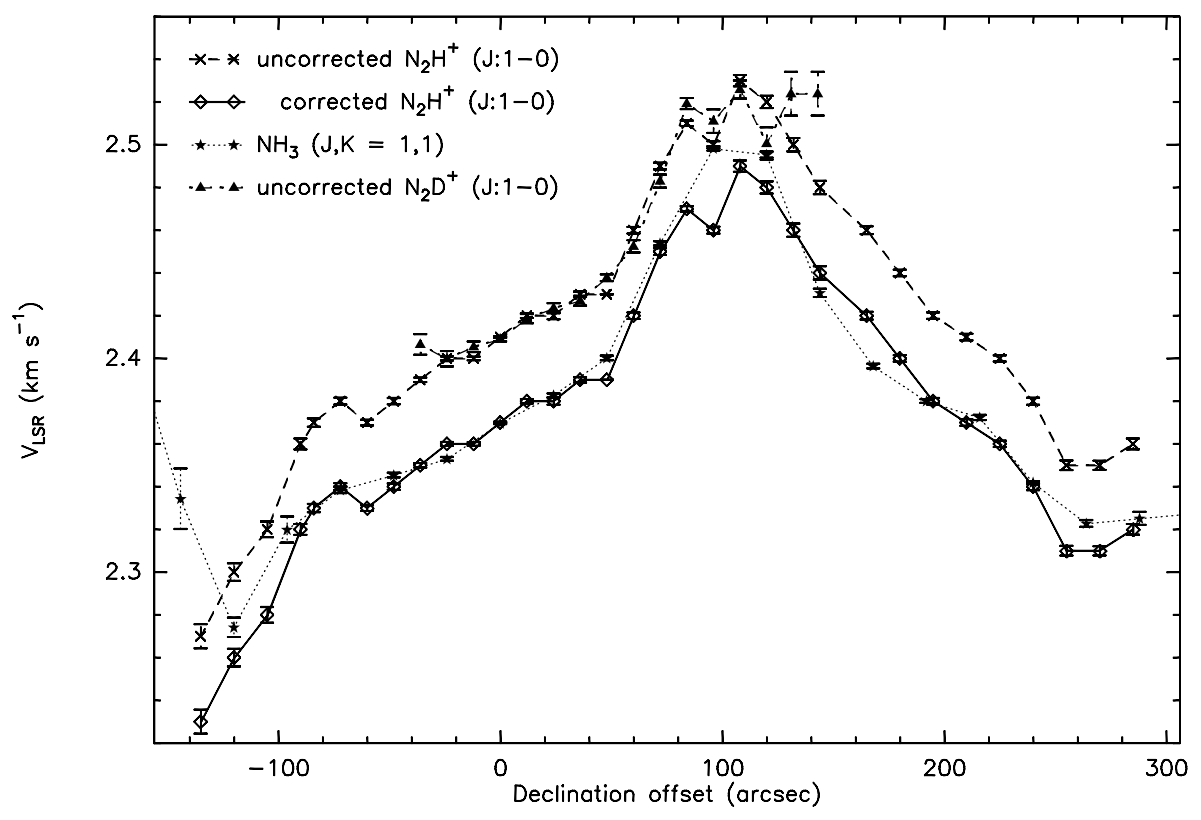

Fig. 2. $\mathrm{N}_{2} \mathrm{H}^{+}, \mathrm{N}_{2} \mathrm{D}^{+}(J: 1-0)$ and $\mathrm{NH}_{3}(1,1)$ line of sight velocity along the $\mathrm{AA}^{\prime}$ cut (see Fig. 1). The $\mathrm{N}_{2} \mathrm{H}^{+}$data are displayed with the original frequency (uncorrected) and with a correction of $-41 \mathrm{~m} \mathrm{~s}^{-1}$. The uncorrected $\mathrm{N}_{2} \mathrm{D}^{+}(J: 1-0)$ points are consistent with the uncorrected $\mathrm{N}_{2} \mathrm{H}^{+}$points despite the different opacities.

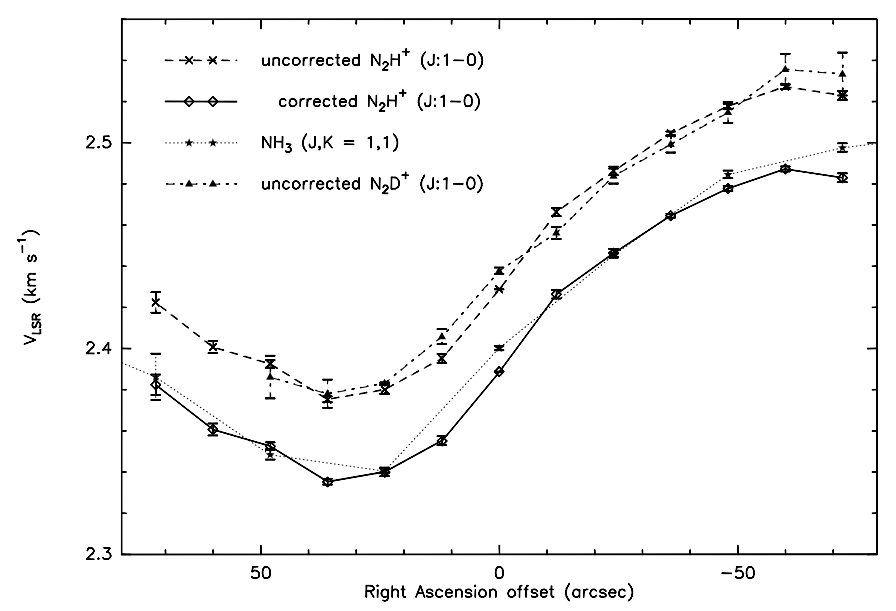

Fig. 3. $\mathrm{N}_{2} \mathrm{H}^{+}, \mathrm{N}_{2} \mathrm{D}^{+}(J: 1-0)$, and $\mathrm{NH}_{3}(1,1)$ line-of-sight velocity along the $\mathrm{BB}^{\prime}$ cut (see Fig. 1). The $\mathrm{N}_{2} \mathrm{H}^{+}$data are displayed with the original frequency (uncorrected) and with a correction of $-41 \mathrm{~m} \mathrm{~s}^{-1}$. The uncorrected $\mathrm{N}_{2} \mathrm{D}^{+}(J: 1-0)$ points are consistent with the uncorrected $\mathrm{N}_{2} \mathrm{H}^{+}$points despite the different opacities.

the velocity gradients be exactly parallel and offset from each other, especially in the probable case of the cylinder rotation. With the present $\mathrm{N}_{2} \mathrm{H}^{+}(\mathrm{J}: 1-0)$ frequency as given by Caselli et al. (1995), there is indeed a clear offset with respect to the $\mathrm{NH}_{3}$ velocity gradient, close to $40 \mathrm{~m} \mathrm{~s}^{-1}$ (and to $26 \mathrm{~m} \mathrm{~s}^{-1}$ compared to the new value in Dore et al. 2004). Amano et al. (2005) also have reinterpreted Caselli et al. (1995) observations along with new laboratory measurements but are therefore plagued by the velocity difference between $\mathrm{N}_{2} \mathrm{H}^{+}$and $\mathrm{C}_{3} \mathrm{H}_{2}$, which appears to exist in view of the present discrepancy between $\mathrm{NH}_{3}$ and $\mathrm{N}_{2} \mathrm{H}^{+}$. Consequently, their best fit (\#2 of their Table 2) is to be considered with caution. Finally, that $\mathrm{N}_{2} \mathrm{D}^{+}$velocity centroids are almost identical to those of $\mathrm{N}_{2} \mathrm{H}^{+}$indicates that the different opacities of the lines do not introduce any measurable bias here (though a very tiny shift is possibly visible in Fig. 3 where the $\mathrm{N}_{2} \mathrm{D}^{+}$displacement is symmetrically slightly less than the $\mathrm{N}_{2} \mathrm{H}^{+}$displacement).

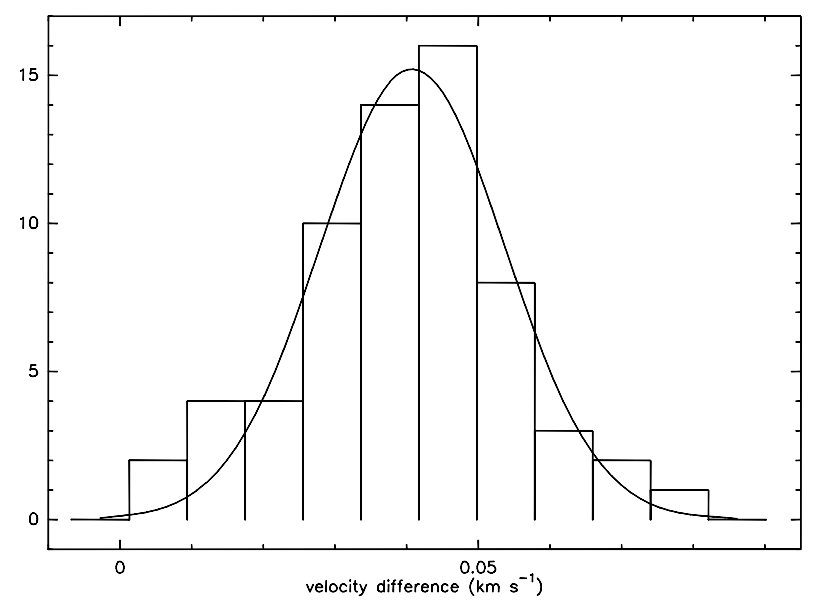

Fig. 4. $\mathrm{N}_{2} \mathrm{H}^{+}(J: 1-0)$ and $\mathrm{NH}_{3}(1,1)$ line-of-sight velocity difference histogram. The Gaussian fit is centered on $40.8 \mathrm{~m} \mathrm{~s}^{-1}$ with a dispersion $\sigma=12.9 \mathrm{~m} \mathrm{~s}^{-1}$

Table 1. Rotation (B) and centrifugal distortion (D) constants for $\mathrm{N}_{2} \mathrm{H}^{+}$ and $\mathrm{N}_{2} \mathrm{D}^{+}$, with errors in parentheses given for the last two digits.

\begin{tabular}{ccc}
\hline \hline Species & $\mathrm{B}$ & $\mathrm{D}$ \\
& $\mathrm{MHz}$ & $\mathrm{MHz}$ \\
\hline $\mathrm{N}_{2} \mathrm{H}^{+}$ & $46586.8713(25)$ & $0.08796(24)$ \\
$\mathrm{N}_{2} \mathrm{D}^{+}$ & $38554.7479(17)$ & $0.06181(15)$ \\
\hline
\end{tabular}

In conclusion, the three species are spatially coexistent and trace the same velocities, and one must adjust the frequencies of $\mathrm{N}_{2} \mathrm{H}^{+}$and $\mathrm{N}_{2} \mathrm{D}^{+}$to that of $\mathrm{NH}_{3}$.

\section{Frequency corrections}

\section{1. $\mathrm{N}_{2} \mathrm{H}^{+}$(J: 1-0) correction}

Frequency was measured using the MINIMIZE function in $\mathrm{CLASS}^{1}$ with the HFS method for all species. For $\mathrm{NH}_{3}$, the

${ }^{1}$ http://wWw.iram.fr/IRAMFR/GILDAS 
Table 2. Hyperfine components and $A_{u l}$ Einstein spontaneous emission coefficients of the $(J: 1-0)$ transition of $\mathrm{N}_{2} \mathrm{H}^{+}$.

\begin{tabular}{cccccccc}
\hline \hline$J^{\prime}$ & $F_{1}^{\prime}$ & $F^{\prime} \rightarrow J$ & $F_{1}$ & $F$ & $\begin{array}{c}\text { Frequency } \\
(\mathrm{MHz})\end{array}$ & $\begin{array}{c}A_{u l} \\
\left(\mathrm{~s}^{-1}\right)\end{array}$ \\
\hline 1 & 1 & 0 & 0 & 1 & 1 & 93171.6081 & $3.628(-5)^{b}$ \\
1 & 1 & 2 & 0 & 1 & 2 & 93171.9049 & $2.721(-5)$ \\
1 & 1 & 2 & 0 & 1 & 1 & 93171.9049 & $9.069(-6)$ \\
1 & 1 & 1 & 0 & 1 & 0 & 93172.0398 & $1.209(-5)$ \\
1 & 1 & 1 & 0 & 1 & 2 & 93172.0398 & $1.512(-5)$ \\
1 & 1 & 1 & 0 & 1 & 1 & 93172.0398 & $9.069(-6)$ \\
1 & 2 & 2 & 0 & 1 & 1 & 93173.4669 & $2.721(-5)$ \\
1 & 2 & 2 & 0 & 1 & 2 & 93173.4669 & $9.070(-6)$ \\
1 & 2 & 3 & 0 & 1 & 2 & 93173.7637 & $3.628(-5)$ \\
1 & 2 & 1 & 0 & 1 & 2 & 93173.9540 & $1.008(-6)$ \\
1 & 2 & 1 & 0 & 1 & 1 & 93173.9540 & $1.512(-5)$ \\
1 & 2 & 1 & 0 & 1 & 0 & 93173.9540 & $2.016(-5)$ \\
1 & 0 & 1 & 0 & 1 & 1 & 93176.2522 & $1.209(-5)$ \\
1 & 0 & 1 & 0 & 1 & 2 & 93176.2522 & $2.016(-5)$ \\
1 & 0 & 1 & 0 & 1 & 0 & 93176.2522 & $4.031(-6)$ \\
\hline
\end{tabular}

${ }^{a}$ The frequency uncertainty is $\pm 4.0 \mathrm{kHz}$ for all hyperfine components; b $3.628(-5)$ means $3.628 \times 10^{-5}$.

Table 3. Hyperfine components and $A_{u l}$ Einstein spontaneous emission coefficients of the $(J: 2-1)$ transition of $\mathrm{N}_{2} \mathrm{H}^{+}$.

\begin{tabular}{cccccccc}
\hline \hline$J^{\prime}$ & $F_{1}^{\prime}$ & $F^{\prime} \rightarrow J$ & $F_{1}$ & $F$ & $\begin{array}{c}\text { Frequency }^{a} \\
(\mathrm{MHz})\end{array}$ & $\begin{array}{c}A_{u l} \\
\left(\mathrm{~s}^{-1}\right)\end{array}$ \\
\hline 2 & 2 & 2 & 1 & 2 & 1 & 186342.4666 & $1.306(-5)$ \\
2 & 2 & 2 & 1 & 2 & 3 & 186342.6570 & $1.354(-5)$ \\
2 & 2 & 1 & 1 & 2 & 1 & 186342.7883 & $6.530(-5)$ \\
2 & 2 & 3 & 1 & 2 & 3 & 186342.9123 & $7.739(-5)$ \\
2 & 2 & 2 & 1 & 2 & 2 & 186342.9537 & $6.046(-5)$ \\
2 & 1 & 1 & 1 & 0 & 1 & 186343.0459 & $1.935(-4)$ \\
2 & 2 & 3 & 1 & 2 & 2 & 186343.2091 & $9.674(-6)$ \\
2 & 1 & 2 & 1 & 0 & 1 & 186343.2577 & $1.935(-4)$ \\
2 & 2 & 1 & 1 & 2 & 2 & 186343.2755 & $2.177(-5)$ \\
2 & 1 & 0 & 1 & 0 & 1 & 186343.5098 & $1.935(-4)$ \\
2 & 2 & 2 & 1 & 1 & 1 & 186344.3808 & $1.959(-4)$ \\
2 & 3 & 3 & 1 & 2 & 3 & 186344.4444 & $3.870(-5)$ \\
2 & 2 & 2 & 1 & 1 & 2 & 186344.5158 & $6.530(-5)$ \\
2 & 2 & 1 & 1 & 1 & 1 & 186344.7026 & $1.088(-4)$ \\
2 & 3 & 3 & 1 & 2 & 2 & 186344.7412 & $3.096(-4)$ \\
2 & 3 & 2 & 1 & 2 & 1 & 186344.7615 & $2.925(-4)$ \\
2 & 2 & 3 & 1 & 1 & 2 & 186344.7711 & $2.612(-4)$ \\
2 & 2 & 1 & 1 & 1 & 2 & 186344.8375 & $7.255(-6)$ \\
2 & 3 & 4 & 1 & 2 & 3 & 186344.8419 & $3.483(-4)$ \\
2 & 3 & 2 & 1 & 2 & 3 & 186344.9519 & $1.548(-6)$ \\
2 & 2 & 1 & 1 & 1 & 0 & 186345.1343 & $1.451(-4)$ \\
2 & 3 & 2 & 1 & 2 & 2 & 186345.2487 & $5.417(-5)$ \\
2 & 1 & 1 & 1 & 2 & 1 & 186345.3441 & $2.418(-6)$ \\
2 & 1 & 2 & 1 & 2 & 1 & 186345.5559 & $9.674(-8)$ \\
2 & 1 & 2 & 1 & 2 & 3 & 186345.7462 & $8.126(-6)$ \\
2 & 1 & 0 & 1 & 2 & 1 & 186345.8080 & $9.674(-6)$ \\
2 & 1 & 1 & 1 & 2 & 2 & 186345.8312 & $7.256(-6)$ \\
2 & 1 & 2 & 1 & 2 & 2 & 186346.0430 & $1.451(-6)$ \\
2 & 1 & 1 & 1 & 1 & 1 & 186347.2584 & $3.628(-5)$ \\
2 & 1 & 1 & 1 & 1 & 2 & 186347.3933 & $6.046(-5)$ \\
2 & 1 & 2 & 1 & 1 & 1 & 186347.4701 & $3.628(-5)$ \\
2 & 1 & 2 & 1 & 1 & 2 & 186347.6050 & $1.088(-4)$ \\
2 & 1 & 1 & 1 & 1 & 0 & 186347.6901 & $4.837(-5)$ \\
2 & 1 & 0 & 1 & 1 & 1 & 186347.7222 & $1.451(-4)$ \\
\hline & & & & & & & \\
\hline
\end{tabular}

${ }^{a}$ The frequency uncertainty is $\pm 2.3 \mathrm{kHz}$ for all hyperfine components.

HFS method is similar to the internally built NH3(1, 1) method. Because it is easier to deal with velocity offsets in CLASS,
Table 4. Hyperfine components and $A_{u l}$ Einstein spontaneous emission coefficients of the $(J: 3-2)$ transition of $\mathrm{N}_{2} \mathrm{H}^{+}$.

\begin{tabular}{|c|c|c|c|c|c|c|c|}
\hline$J^{\prime}$ & $\overline{F_{1}^{\prime}}$ & $\overline{F^{\prime}}$ & $\rightarrow J$ & $\overline{F_{1}}$ & $\bar{F}$ & $\begin{array}{l}\text { Frequency }^{a} \\
(\mathrm{MHz})\end{array}$ & $\begin{array}{c}A_{u l} \\
\left(\mathrm{~s}^{-1}\right)\end{array}$ \\
\hline 3 & 3 & 3 & 2 & 3 & 2 & 279509.361 & $1.110(-5)$ \\
\hline 3 & 3 & 3 & 2 & 3 & 4 & 279509.471 & $1.124(-5)$ \\
\hline 3 & 3 & 2 & 2 & 3 & 2 & 279509.795 & $1.244(-4)$ \\
\hline 3 & 3 & 4 & 2 & 3 & 4 & 279509.849 & $1.312(-4)$ \\
\hline 3 & 3 & 3 & 2 & 3 & 3 & 279509.868 & $1.176(-4)$ \\
\hline 3 & 3 & 4 & 2 & 3 & 3 & 279510.246 & $8.745(-6)$ \\
\hline 3 & 3 & 2 & 2 & 3 & 3 & 279510.302 & $1.555(-5)$ \\
\hline 3 & 2 & 2 & 2 & 1 & 2 & 279511.103 & $2.644(-4)$ \\
\hline 3 & 2 & 2 & 2 & 1 & 1 & 279511.315 & $7.933(-4)$ \\
\hline 3 & 2 & 1 & 2 & 1 & 0 & 279511.355 & $5.876(-4)$ \\
\hline 3 & 4 & 4 & 2 & 3 & 4 & 279511.384 & $7.870(-5)$ \\
\hline 3 & 3 & 3 & 2 & 2 & 3 & 279511.401 & $1.244(-4)$ \\
\hline 3 & 2 & 3 & 2 & 1 & 2 & 279511.479 & $1.058(-3)$ \\
\hline 3 & 2 & 1 & 2 & 1 & 2 & 279511.607 & $2.938(-5)$ \\
\hline 3 & 3 & 3 & 2 & 2 & 2 & 279511.656 & $9.950(-4)$ \\
\hline 3 & 3 & 2 & 2 & 2 & 1 & 279511.768 & $9.402(-4)$ \\
\hline 3 & 3 & 4 & 2 & 2 & 3 & 279511.778 & $1.119(-3)$ \\
\hline 3 & 4 & 3 & 2 & 3 & 2 & 279511.780 & $1.156(-3)$ \\
\hline 3 & 4 & 4 & 2 & 3 & 3 & 279511.781 & $1.181(-3)$ \\
\hline 3 & 2 & 1 & 2 & 1 & 1 & 279511.819 & $4.407(-4)$ \\
\hline 3 & 4 & 5 & 2 & 3 & 4 & 279511.832 & $1.259(-3)$ \\
\hline 3 & 3 & 2 & 2 & 2 & 3 & 279511.834 & $4.975(-6)$ \\
\hline 3 & 4 & 3 & 2 & 3 & 4 & 279511.890 & $1.606(-6)$ \\
\hline 3 & 2 & 2 & 2 & 3 & 2 & 279511.897 & $6.218(-7)$ \\
\hline 3 & 3 & 2 & 2 & 2 & 2 & 279512.090 & $1.741(-4)$ \\
\hline 3 & 2 & 3 & 2 & 3 & 2 & 279512.273 & $1.269(-8)$ \\
\hline 3 & 4 & 3 & 2 & 3 & 3 & 279512.287 & $1.012(-4)$ \\
\hline 3 & 2 & 3 & 2 & 3 & 4 & 279512.383 & $5.140(-6)$ \\
\hline 3 & 2 & 1 & 2 & 3 & 2 & 279512.401 & $5.597(-6)$ \\
\hline 3 & 2 & 2 & 2 & 3 & 3 & 279512.405 & $4.975(-6)$ \\
\hline 3 & 2 & 3 & 2 & 3 & 3 & 279512.781 & $4.442(-7)$ \\
\hline 3 & 2 & 2 & 2 & 2 & 1 & 279513.870 & $2.938(-5)$ \\
\hline 3 & 2 & 2 & 2 & 2 & 3 & 279513.937 & $3.047(-5)$ \\
\hline 3 & 2 & 2 & 2 & 2 & 2 & 279514.192 & $1.360(-4)$ \\
\hline 3 & 2 & 3 & 2 & 2 & 3 & 279514.313 & $1.741(-4)$ \\
\hline 3 & 2 & 1 & 2 & 2 & 1 & 279514.374 & $1.469(-4)$ \\
\hline 3 & 2 & 3 & 2 & 2 & 2 & 279514.568 & $2.177(-5)$ \\
\hline 3 & 2 & 1 & 2 & 2 & 2 & 279514.696 & $4.897(-5)$ \\
\hline
\end{tabular}

${ }^{a}$ The frequency uncertainty is $\pm 11 \mathrm{kHz}$ for all hyperfine components.

especially as we have to compare two species at different frequencies, the measurements have all been made on the velocity scale. Velocity differences are subsequently converted into frequency offsets using the approximate Doppler-shift formula $\left(v=v_{0}\left(1-\frac{\delta v}{c}\right), \delta v\right.$ being the velocity offset, $c$ the celerity of light, $v$ and $v_{0}$ the corrected and original frequencies). To fit all the hyperfine components individually, the HFS method requires that we provide their list with their relative velocities and relative weights, these parameters not being adjusted during the fit. Therefore, we used the detailed HFS provided by Caselli et al. (1995), Dore et al. (2004), and Kukolich (1967). Since an accurate determination of the hyperfine spectroscopic constants only slightly depends on the adopted rotational constants $\mathrm{B}$ and $\mathrm{D}^{2}$, we can safely use the previously determined ones. In doing so, our own determination for the relative velocity offsets between the hyperfine components in the $J: 1-0$ line agree with

\footnotetext{
2 Indeed, it can be noted that the HFS splitting is, in a first approximation, identical for both $\mathrm{N}_{2} \mathrm{H}^{+}$and $\mathrm{N}_{2} \mathrm{D}^{+}$despite a large, $\sim 20 \%$ variation in $\mathrm{B}$ rotational constant
} 
Table 5. Hyperfine components and $A_{u l}$ Einstein spontaneous emission coefficients of the $(J: 4-3)$ transition of $\mathrm{N}_{2} \mathrm{H}^{+}$.

\begin{tabular}{|c|c|c|c|c|c|c|c|}
\hline$\overline{J^{\prime}}$ & $\overline{F_{1}^{\prime}}$ & $\bar{F}$ & & $\overline{F_{1}}$ & $\bar{F}$ & $\begin{array}{c}\text { Frequency }^{a} \\
(\mathrm{MHz})\end{array}$ & $\begin{array}{c}A_{u l} \\
\left(\mathrm{~s}^{-1}\right)\end{array}$ \\
\hline 4 & 4 & 4 & 3 & 4 & 3 & 372670.005 & $9.404(-6)$ \\
\hline 4 & 4 & 4 & 3 & 4 & 5 & 372670.062 & $9.457(-6)$ \\
\hline 4 & 4 & 3 & 3 & 4 & 3 & 372670.467 & $1.814(-4)$ \\
\hline 4 & 4 & 5 & 3 & 4 & 5 & 372670.500 & $1.857(-4)$ \\
\hline 4 & 4 & 4 & 3 & 4 & 4 & 372670.510 & $1.746(-4)$ \\
\hline 4 & 4 & 5 & 3 & 4 & 4 & 372670.948 & $7.738(-6)$ \\
\hline 4 & 4 & 3 & 3 & 4 & 4 & 372670.972 & $1.209(-5)$ \\
\hline 4 & 3 & 3 & 3 & 2 & 3 & 3726 & $3.158(-4)$ \\
\hline 4 & 5 & 5 & 3 & 4 & 5 & 3726 & $1.238(-4)$ \\
\hline 4 & 4 & 4 & 3 & 3 & 4 & 372 & 1.814( \\
\hline 4 & 3 & 3 & 3 & 2 & & 3726 & 2.527 \\
\hline 4 & 3 & 2 & 3 & 2 & 1 & 3726 & 2.388( \\
\hline 4 & 3 & 4 & 3 & 2 & 3 & 3726 & 2.843( \\
\hline 4 & 3 & 3 & 3 & 4 & 3 & 372672.398 & $2.467(-7)$ \\
\hline 4 & 3 & 2 & 3 & 2 & 3 & 372672.408 & $1.263(-5)$ \\
\hline 4 & 4 & 4 & 3 & 3 & 3 & 3726 & $2.720(-3)$ \\
\hline 4 & 4 & 3 & 3 & 3 & 2 & 3726 & $2.665(-3)$ \\
\hline 4 & 4 & 5 & 3 & 3 & 4 & 3726 & $2.902(-3)$ \\
\hline 4 & 5 & 4 & 3 & 4 & 3 & 3726 & $2.942(-3)$ \\
\hline 4 & 5 & 5 & 3 & 4 & 4 & 3726 & $2.971(-3)$ \\
\hline 4 & 4 & 3 & 3 & 3 & 4 & 3726 & $3.701(-6)$ \\
\hline 4 & 5 & 6 & 3 & 4 & 5 & 372 & $3.095(-3)$ \\
\hline 4 & 5 & 4 & 3 & 4 & 5 & 3726 & $1.528(-6)$ \\
\hline 4 & 3 & 2 & 3 & 2 & 2 & 372 & 4.422 \\
\hline 4 & 3 & 4 & 3 & 4 & 3 & 372 & 3.046 \\
\hline 4 & 4 & 3 & 3 & 3 & 3 & 3726 & $2.332(-4)$ \\
\hline 4 & 3 & 4 & 3 & 4 & 5 & 3726 & $3.753(-6)$ \\
\hline 4 & 3 & 2 & 3 & 4 & 3 & 372672.902 & $3.948(-6)$ \\
\hline 4 & 3 & 3 & 3 & 4 & 4 & 372672.903 & $3.701(-6)$ \\
\hline 4 & 5 & 4 & 3 & 4 & 4 & 3726 & $1.513(-4)$ \\
\hline 4 & 3 & 4 & 3 & 4 & 4 & 372673.347 & $1.919(-7)$ \\
\hline 4 & 3 & 3 & 3 & 3 & 2 & 372674.383 & $1.974(-5)$ \\
\hline 4 & 3 & 3 & 3 & 3 & 4 & 372674.439 & $1.999(-5)$ \\
\hline 4 & 3 & 3 & 3 & 3 & 3 & 372674.816 & $2.090(-4)$ \\
\hline 4 & 3 & 4 & 3 & 3 & 4 & 372674.883 & $2.332(-4)$ \\
\hline 4 & 3 & 2 & 3 & 3 & 2 & 372674.887 & $2.211(-4)$ \\
\hline 4 & 3 & 4 & 3 & 3 & 3 & 372675.260 & $1.555(-5)$ \\
\hline 4 & 3 & 2 & 3 & 3 & 3 & 372675.320 & $2.764(-5)$ \\
\hline
\end{tabular}

${ }^{a}$ The frequency uncertainty is $\pm 41 \mathrm{kHz}$ for all hyperfine components.

Caselli et al. (1995) with a typical dispersion of $0.7 \mathrm{kHz}$. Though this is twice as much as the rms error on our frequency determination of each individual component $(\sigma \sim 0.3 \mathrm{kHz})$, we find that using their offsets or ours introduces a negligible difference of $0.13 \mathrm{kHz}$ in the $J: 1-0$ transition frequency determination, which is comparable to the rms error of the fit $(0.12 \mathrm{kHz})$. We also did not find any improvement on the rms error of the fit itself. For the $\mathrm{N}_{2} \mathrm{H}^{+}$and $\mathrm{N}_{2} \mathrm{D}^{+}$transitions, the strongest hyperfine transition was given null velocity offset, as it was also the strongest hyperfine transition frequency used to tune the receivers. The advantage of a complex and strong HFS is that it lowers the uncertainty on the velocity fit, compared to a single line estimate (fitting the $\mathrm{N}_{2} \mathrm{H}^{+} J: 1-0$ lines individually with independent Gaussians, gives errors between 0.85 and $1.2 \mathrm{~m} \mathrm{~s}^{-1}$ instead of $0.38 \mathrm{~m} \mathrm{~s}^{-1}$ with the global HFS fit for the reference spectrum).

Though the reference position has been observed often enough to get very high signal-to-noise ratios for most transitions, it seems more secure to measure the offset between $\mathrm{N}_{2} \mathrm{H}^{+}$ and $\mathrm{NH}_{3}$ on all common positions (every other position in the
Table 6. Hyperfine components and $A_{u l}$ Einstein spontaneous emission coefficients of the $(J: 5-4)$ transition of $\mathrm{N}_{2} \mathrm{H}^{+}$.

\begin{tabular}{|c|c|c|c|c|c|c|c|}
\hline$J^{\prime}$ & $F_{1}^{\prime}$ & $\bar{F}$ & $\rightarrow J$ & $F_{1}$ & $\bar{F}$ & $\begin{array}{c}\text { Frequency }^{a} \\
(\mathrm{MHz})\end{array}$ & $\begin{array}{l}A_{u l} \\
\left(\mathrm{~s}^{-1}\right)\end{array}$ \\
\hline 5 & 5 & 5 & 4 & 5 & 4 & 465822.236 & $8.093(-6)$ \\
\hline 5 & 5 & 5 & 4 & 5 & 6 & 465822.254 & $8.118(-6)$ \\
\hline 5 & 5 & 4 & 4 & 5 & 4 & 465822.704 & $2.374(-4)$ \\
\hline 5 & 5 & 6 & 4 & 5 & 6 & 465822.729 & $2.404(-4)$ \\
\hline 5 & 5 & 5 & 4 & 5 & 5 & 465822.734 & $2.311(-4)$ \\
\hline 5 & 5 & 4 & 4 & 5 & 5 & 465823.202 & $9.891(-6)$ \\
\hline 5 & 5 & 6 & 4 & 5 & 5 & 465823.209 & $6.869(-6)$ \\
\hline 5 & 4 & 4 & 4 & 3 & 4 & 465824.191 & $3.673(-4)$ \\
\hline 5 & 5 & 5 & 4 & 4 & 5 & 465824.279 & $2.374(-4)$ \\
\hline 5 & 6 & 6 & 4 & 5 & 6 & 465824.285 & $1.717(-4)$ \\
\hline 5 & 4 & 4 & 4 & 5 & 4 & 465824.546 & $1.221(-7)$ \\
\hline 5 & 4 & 3 & 4 & 3 & 2 & 465824.627 & $5.397(-3)$ \\
\hline 5 & 4 & 4 & 4 & 3 & 3 & 465824.635 & $5.509(-3)$ \\
\hline 5 & 4 & 5 & 4 & 3 & 4 & 465824.673 & $5.877(-3)$ \\
\hline 5 & 4 & 3 & 4 & 3 & 4 & 465824.687 & $7.496(-6)$ \\
\hline 5 & 5 & 5 & 4 & 4 & 4 & 465824.717 & $5.697(-3)$ \\
\hline 5 & 5 & 4 & 4 & 4 & 3 & 465824.723 & $5.642(-3)$ \\
\hline 5 & 5 & 4 & 4 & 4 & 5 & 465824.747 & $2.931(-6)$ \\
\hline 5 & 5 & 6 & 4 & 4 & 5 & 465824.754 & $5.935(-3)$ \\
\hline 5 & 6 & 5 & 4 & 5 & 4 & 465824.756 & $5.978(-3)$ \\
\hline 5 & 6 & 6 & 4 & 5 & 5 & 465824.765 & $6.010(-3)$ \\
\hline 5 & 6 & 5 & 4 & 5 & 6 & 465824.774 & $1.419(-6)$ \\
\hline 5 & 6 & 7 & 4 & 5 & 6 & 465824.788 & $6.182(-3)$ \\
\hline 5 & 4 & 5 & 4 & 5 & 4 & 465825.029 & $1.009(-9)$ \\
\hline 5 & 4 & 3 & 4 & 5 & 4 & 465825.042 & $3.053(-6)$ \\
\hline 5 & 4 & 4 & 4 & 5 & 5 & 465825.045 & $2.931(-6)$ \\
\hline 5 & 4 & 5 & 4 & 5 & 6 & 465825.047 & $2.952(-6)$ \\
\hline 5 & 4 & 3 & 4 & 3 & 3 & 465825.131 & $4.722(-4)$ \\
\hline 5 & 5 & 4 & 4 & 4 & 4 & 465825.185 & $2.901(-4)$ \\
\hline 5 & 6 & 5 & 4 & 5 & 5 & 465825.254 & $2.029(-4)$ \\
\hline 5 & 4 & 5 & 4 & 5 & 5 & 465825.527 & $9.991(-8)$ \\
\hline 5 & 4 & 4 & 4 & 4 & 3 & 465826.566 & $1.469(-5)$ \\
\hline 5 & 4 & 4 & 4 & 4 & 5 & 465826.590 & $1.478(-5)$ \\
\hline 5 & 4 & 4 & 4 & 4 & 4 & 465827.028 & $2.728(-4)$ \\
\hline 5 & 4 & 3 & 4 & 4 & 3 & 465827.062 & $2.833(-4)$ \\
\hline 5 & 4 & 5 & 4 & 4 & 5 & 465827.072 & $2.902(-4)$ \\
\hline 5 & 4 & 5 & 4 & 4 & 4 & 465827.510 & $1.209(-5)$ \\
\hline 5 & 4 & 3 & 4 & 4 & 4 & 465827.524 & $1.889(-5)$ \\
\hline
\end{tabular}

${ }^{a}$ The frequency uncertainty is $\pm 95 \mathrm{kHz}$ for all hyperfine components.

central core, a few positions in the rest of the cloud) and measure the average difference. We have identified 65 common positions with sufficient signal-to-noise ratios and obtained the dispersion histogram of the velocity difference (Fig. 4). After fitting the histogram with a Gaussian, we find a velocity difference of $40.8 \mathrm{~m} \mathrm{~s}^{-1}$ with a dispersion $\sigma=12.9 \mathrm{~m} \mathrm{~s}^{-1}$. This corresponds to a frequency correction of $-13 \pm 4 \mathrm{kHz}$ (or $-8.8 \mathrm{kHz}$ compared to Dore et al. 2004). For the reference position alone, the difference is also $40.8 \mathrm{~m} \mathrm{~s}^{-1}$ with an error $\sigma=0.56 \mathrm{~m} \mathrm{~s}^{-1}$ (due to the very high signal-to-noise ratio obtained for both lines towards that position).

\section{2. $\mathrm{N}_{2} \mathrm{H}^{+}$(J: 3-2) correction}

For the $\mathrm{N}_{2} \mathrm{H}^{+}(J: 3-2)$ transition, only the reference position has been observed with a reasonably good signal-to-noise ratio $(\sim 10)$. Therefore, we can only make a direct comparison for this position. The Jet Propulsion Laboratory (JPL) catalog frequency for this line $(279511.701 \pm 0.05 \mathrm{MHz})$ is too vague to be useful for a precise velocity determination. The Cologne 
Table 7. Hyperfine components and $A_{u l}$ Einstein spontaneous emission coefficients of the $(J: 6-5)$ transition of $\mathrm{N}_{2} \mathrm{H}^{+}$.

\begin{tabular}{|c|c|c|c|c|c|c|c|}
\hline$\overline{J^{\prime}}$ & $\bar{F}_{1}^{\prime}$ & $\overline{F^{\prime}}$ & $\rightarrow J$ & $\overline{F_{1}}$ & $\bar{F}$ & $\begin{array}{l}\text { Frequency }^{a} \\
(\mathrm{MHz})\end{array}$ & $\begin{array}{c}A_{u l} \\
\left(\mathrm{~s}^{-1}\right)\end{array}$ \\
\hline 6 & 6 & 6 & 5 & 6 & 7 & 558963.91 & $7.094(-6)$ \\
\hline 6 & 6 & 6 & 5 & 6 & 5 & 558963.93 & $7.081(-6)$ \\
\hline 6 & 6 & 5 & 5 & 6 & 5 & 558964.39 & $2.929(-4)$ \\
\hline 6 & 6 & 7 & 5 & 6 & 7 & 558964.41 & $2.951(-4)$ \\
\hline 6 & 6 & 6 & 5 & 6 & 6 & 558964.42 & $2.871(-4)$ \\
\hline 6 & 6 & 5 & 5 & 6 & 6 & 558 & $8.368(-6)$ \\
\hline 6 & 6 & 7 & 5 & 6 & 6 & 558 & $6.148(-6)$ \\
\hline 6 & 5 & 5 & 5 & 4 & & 5589 & $4.195(-4)$ \\
\hline 6 & 6 & 6 & 5 & 5 & & 5589 & $2.929(-4)$ \\
\hline 6 & 7 & 7 & 5 & 6 & & 558 & $2.213(-4)$ \\
\hline 6 & 5 & 5 & 5 & 6 & & 558966.18 & $6.916(-8)$ \\
\hline 6 & 5 & 4 & 5 & 4 & & 558966.38 & $9.969(-3)$ \\
\hline 6 & 5 & 5 & 5 & 4 & & 558966.39 & $1.007(-2)$ \\
\hline 6 & 5 & 4 & 5 & 4 & 5 & 558966.39 & $5.179(-6)$ \\
\hline 6 & 5 & 6 & 5 & 4 & 5 & 558966.42 & $1.049(-2)$ \\
\hline 6 & 6 & 5 & 5 & 5 & 6 & 558966.44 & $2.421(-6)$ \\
\hline 6 & 6 & 5 & 5 & 5 & 4 & 558 & $1.020(-2)$ \\
\hline 6 & 6 & 6 & 5 & 5 & 5 & 558 & $1.025(-2)$ \\
\hline 6 & 7 & 6 & 5 & 6 & 7 & 558 & $1.310(-6)$ \\
\hline 6 & 6 & 7 & 5 & 5 & 6 & 558 & $1.054(-2)$ \\
\hline 6 & 7 & 6 & 5 & 6 & 5 & 558 & $1.059(-2)$ \\
\hline 6 & 7 & 7 & 5 & 6 & & 558 & $1.062(-2)$ \\
\hline 6 & 7 & 8 & 5 & 6 & & 558 & $1.085(-2)$ \\
\hline 6 & 5 & 4 & 5 & 6 & & 558 & $2.490(-6)$ \\
\hline 6 & 5 & 5 & 5 & 6 & & 558 & $2.421(-6)$ \\
\hline 6 & 5 & 6 & 5 & 6 & & 558966.68 & $2.431(-6)$ \\
\hline 6 & 5 & 6 & 5 & 6 & & 558966.69 & $4.092 e-10$ \\
\hline 6 & 5 & 4 & 5 & 4 & 4 & 558966.88 & $5.127(-4)$ \\
\hline 6 & 6 & 5 & 5 & 5 & 5 & 558966.91 & $3.462(-4)$ \\
\hline 6 & 7 & 6 & 5 & 6 & 6 & 558966.96 & $2.554(-4)$ \\
\hline 6 & 5 & 6 & 5 & 6 & 6 & 558967.18 & $5.852(-8)$ \\
\hline 6 & 5 & 5 & 5 & 5 & 6 & 558968.27 & $1.169(-5)$ \\
\hline 6 & 5 & 5 & 5 & 5 & & 558968.23 & $1.165(-5)$ \\
\hline 6 & 5 & 5 & 5 & 5 & & 558968.70 & $3.327(-4)$ \\
\hline 6 & 5 & 4 & 5 & 5 & & 558968.72 & $3.418(-4)$ \\
\hline 6 & 5 & 6 & 5 & 5 & & 558968.74 & $3.462(-4)$ \\
\hline 6 & 5 & 4 & 5 & 5 & & 558969.19 & $1.424(-5)$ \\
\hline 6 & 5 & 6 & 5 & 5 & 5 & 558969.21 & $9.890(-6)$ \\
\hline
\end{tabular}

a The frequency uncertainty is $\pm 0.18 \mathrm{MHz}$ for all hyperfine components.

Table 8. Hyperfine components and $A_{u l}$ Einstein spontaneous emission coefficients of the $(J: 1-0)$ transition of $\mathrm{N}_{2} \mathrm{D}^{+}$.

\begin{tabular}{|c|c|c|c|c|c|c|c|}
\hline$J^{\prime}$ & $F_{1}^{\prime}$ & & & $F_{1}$ & $F$ & $\begin{array}{c}\text { Frequency }^{a} \\
(\mathrm{MHz})\end{array}$ & $\begin{array}{c}A_{u l} \\
\left(\mathrm{~s}^{-1}\right)\end{array}$ \\
\hline 1 & 1 & 0 & 0 & 1 & 1 & 77107.4757 & $2.056(-5)$ \\
\hline 1 & 1 & 2 & 0 & 1 & 7 & 77107.7671 & $1.542(-5)$ \\
\hline 1 & 1 & 2 & 0 & 1 & 1 & 77107.7671 & $5.140(-6)$ \\
\hline 1 & 1 & 1 & 0 & 1 & 1 & 77107.9023 & $5.140(-6)$ \\
\hline 1 & 1 & 1 & 0 & 1 & 0 & 77107.9023 & $6.854(-6)$ \\
\hline 1 & 1 & 1 & 0 & 1 & 2 & 77107.9023 & $8.568(-6)$ \\
\hline 1 & 2 & 2 & 0 & 1 & 1 & 77109.3248 & $1.542(-5)$ \\
\hline 1 & 2 & 2 & 0 & 1 & 2 & 77109 & $5.141(-6)$ \\
\hline 1 & 2 & 3 & 0 & 1 & 2 & 77109.6162 & $2.056(-5)$ \\
\hline 1 & 2 & 1 & 0 & 1 & 0 & 7710 & $1.142(-5)$ \\
\hline 1 & 2 & 1 & 0 & 1 & 2 & 77109.8104 & $5.712(-7)$ \\
\hline 1 & 2 & 1 & 0 & 1 & & 77109.8104 & $8.568(-6)$ \\
\hline 1 & 0 & 1 & 0 & 1 & & 77112.10 & $1.142(-5)$ \\
\hline 1 & 0 & 1 & 0 & 1 & & 77112.1085 & $2.285(-6)$ \\
\hline 1 & 0 & 1 & 0 & 1 & 1 & 77112.1085 & $6.855(-6)$ \\
\hline
\end{tabular}

${ }^{a}$ The frequency uncertainty is $\pm 2.8 \mathrm{kHz}$ for all hyperfine components.
Table 9. Hyperfine components and $A_{u l}$ Einstein spontaneous emission coefficients of the $(J: 2-1)$ transition of $\mathrm{N}_{2} \mathrm{D}^{+}$.

\begin{tabular}{cccccccc}
\hline \hline$J^{\prime}$ & $F_{1}^{\prime}$ & $F^{\prime} \rightarrow J$ & $F_{1}$ & $F$ & $\begin{array}{c}\text { Frequency }^{a} \\
(\mathrm{MHz})\end{array}$ & $\begin{array}{c}A_{u l} \\
\left(\mathrm{~s}^{-1}\right)\end{array}$ \\
\hline 2 & 2 & 2 & 1 & 2 & 1 & 154214.8196 & $7.402(-6)$ \\
2 & 2 & 2 & 1 & 2 & 3 & 154215.0138 & $7.676(-6)$ \\
2 & 2 & 1 & 1 & 2 & 1 & 154215.1417 & $3.701(-5)$ \\
2 & 2 & 3 & 1 & 2 & 3 & 154215.2619 & $4.387(-5)$ \\
2 & 2 & 2 & 1 & 2 & 2 & 154215.3052 & $3.427(-5)$ \\
2 & 1 & 1 & 1 & 0 & 1 & 154215.3991 & $1.097(-4)$ \\
2 & 2 & 3 & 1 & 2 & 2 & 154215.5533 & $5.483(-6)$ \\
2 & 1 & 2 & 1 & 0 & 1 & 154215.6021 & $1.097(-4)$ \\
2 & 2 & 1 & 1 & 2 & 2 & 154215.6273 & $1.234(-5)$ \\
2 & 1 & 0 & 1 & 0 & 1 & 154215.8617 & $1.097(-4)$ \\
2 & 2 & 2 & 1 & 1 & 1 & 154216.7277 & $1.110(-4)$ \\
2 & 3 & 3 & 1 & 2 & 3 & 154216.7920 & $2.193(-5)$ \\
2 & 2 & 2 & 1 & 1 & 2 & 154216.8629 & $3.701(-5)$ \\
2 & 2 & 1 & 1 & 1 & 1 & 154217.0498 & $6.169(-5)$ \\
2 & 3 & 3 & 1 & 2 & 2 & 154217.0834 & $1.755(-4)$ \\
2 & 3 & 2 & 1 & 2 & 1 & 154217.1055 & $1.658(-4)$ \\
2 & 2 & 3 & 1 & 1 & 2 & 154217.1110 & $1.481(-4)$ \\
2 & 3 & 4 & 1 & 2 & 3 & 154217.1807 & $1.974(-4)$ \\
2 & 2 & 1 & 1 & 1 & 2 & 154217.1850 & $4.113(-6)$ \\
2 & 3 & 2 & 1 & 2 & 3 & 154217.2998 & $8.773(-7)$ \\
2 & 2 & 1 & 1 & 1 & 0 & 154217.4764 & $8.225(-5)$ \\
2 & 3 & 2 & 1 & 2 & 2 & 154217.5912 & $3.071(-5)$ \\
2 & 1 & 1 & 1 & 2 & 1 & 154217.6972 & $1.371(-6)$ \\
2 & 1 & 2 & 1 & 2 & 1 & 154217.9002 & $5.483(-8)$ \\
2 & 1 & 2 & 1 & 2 & 3 & 154218.0944 & $4.606(-6)$ \\
2 & 1 & 0 & 1 & 2 & 1 & 154218.1598 & $5.483(-6)$ \\
2 & 1 & 1 & 1 & 2 & 2 & 154218.1828 & $4.113(-6)$ \\
2 & 1 & 2 & 1 & 2 & 2 & 154218.3858 & $8.225(-7)$ \\
2 & 1 & 1 & 1 & 1 & 1 & 154219.6053 & $2.056(-5)$ \\
2 & 1 & 1 & 1 & 1 & 2 & 154219.7405 & $3.427(-5)$ \\
2 & 1 & 2 & 1 & 1 & 1 & 154219.8083 & $2.056(-5)$ \\
2 & 1 & 2 & 1 & 1 & 2 & 154219.9435 & $6.169(-5)$ \\
2 & 1 & 1 & 1 & 1 & 0 & 154220.0320 & $2.742(-5)$ \\
2 & 1 & 0 & 1 & 1 & 1 & 154220.0679 & $8.225(-5)$ \\
\hline
\end{tabular}

${ }^{a}$ The frequency uncertainty is $\pm 2.1 \mathrm{kHz}$ for all hyperfine components.

Database for Molecular Spectroscopy (CDMS) catalogue gives $v=279511.8577 \mathrm{MHz}$ for the $\left(F_{1} F: 4,5-3,4\right)$ strongest hyperfine component based on various works, while Crapsi et al. (2005) give $279511.863 \mathrm{MHz}$ determined from the new rotational and centrifugal distortion constants from Dore et al. (2004). These new values are respectively 26 and $31 \mathrm{kHz}$ above our own determination.

\section{3. $\mathrm{N}_{2} D^{+}$corrections}

For all three transitions of $\mathrm{N}_{2} \mathrm{D}^{+}$, we took advantage of the similar sampling with $\mathrm{N}_{2} \mathrm{H}^{+}(J: 1-0)$ to have more comparison points. We obtained 83,73 , and 51 comparison points with a high enough signal-to-noise ratio between $\mathrm{N}_{2} \mathrm{H}^{+}(J: 1-0)$ (using Caselli et al. 1995, frequency) and $\mathrm{N}_{2} \mathrm{D}^{+}(J: 1-0),(J: 2-1)$, and $(J: 3-2)$ transitions, respectively. The Gaussian fit to each histogram yielded

$$
\begin{aligned}
& (J: 1-0):-5.1 \mathrm{~m} \mathrm{~s}^{-1}\left(\sigma=10.5 \mathrm{~m} \mathrm{~s}^{-1}\right) \\
& (J: 2-1): 12.5 \mathrm{~m} \mathrm{~s}^{-1}\left(\sigma=14.4 \mathrm{~m} \mathrm{~s}^{-1}\right) \\
& (J: 3-2): 18.4 \mathrm{~m} \mathrm{~s}^{-1}\left(\sigma=8.1 \mathrm{~m} \mathrm{~s}^{-1}\right)
\end{aligned}
$$


Table 10. Hyperfine components and $A_{u l}$ Einstein spontaneous emission coefficients of the $(J: 3-2)$ transition of $\mathrm{N}_{2} \mathrm{D}^{+}$.

\begin{tabular}{cccccccc}
\hline \hline$J^{\prime}$ & $F_{1}^{\prime}$ & $F^{\prime} \rightarrow J$ & $F_{1}$ & $F$ & $\begin{array}{c}\text { Frequency }^{a} \\
(\mathrm{MHz})\end{array}$ & $\begin{array}{c}A_{u l} \\
\left(\mathrm{~s}^{-1}\right)\end{array}$ \\
\hline 3 & 3 & 3 & 2 & 3 & 2 & 231319.4552 & $6.294(-6)$ \\
3 & 3 & 3 & 2 & 3 & 4 & 231319.5743 & $6.373(-6)$ \\
3 & 3 & 2 & 2 & 3 & 2 & 231319.8904 & $7.049(-5)$ \\
3 & 3 & 4 & 2 & 3 & 4 & 231319.9411 & $7.435(-5)$ \\
3 & 3 & 3 & 2 & 3 & 3 & 231319.9629 & $6.664(-5)$ \\
3 & 3 & 4 & 2 & 3 & 3 & 231320.3297 & $4.957(-6)$ \\
3 & 3 & 2 & 2 & 3 & 3 & 231320.3981 & $8.812(-6)$ \\
3 & 2 & 2 & 2 & 1 & 2 & 231321.1993 & $1.499(-4)$ \\
3 & 2 & 2 & 2 & 1 & 1 & 231321.4023 & $4.497(-4)$ \\
3 & 2 & 1 & 2 & 1 & 0 & 231321.4445 & $3.331(-4)$ \\
3 & 4 & 4 & 2 & 3 & 4 & 231321.4756 & $4.461(-5)$ \\
3 & 3 & 3 & 2 & 2 & 3 & 231321.4930 & $7.050(-5)$ \\
3 & 2 & 3 & 2 & 1 & 2 & 231321.5630 & $5.996(-4)$ \\
3 & 2 & 1 & 2 & 1 & 2 & 231321.7041 & $1.665(-5)$ \\
3 & 3 & 3 & 2 & 2 & 2 & 231321.7411 & $5.640(-4)$ \\
3 & 3 & 2 & 2 & 2 & 1 & 231321.8543 & $5.330(-4)$ \\
3 & 3 & 4 & 2 & 2 & 3 & 231321.8599 & $6.345(-4)$ \\
3 & 4 & 4 & 2 & 3 & 3 & 231321.8643 & $6.692(-4)$ \\
3 & 4 & 3 & 2 & 3 & 2 & 231321.8645 & $6.555(-4)$ \\
3 & 2 & 1 & 2 & 1 & 1 & 231321.9071 & $2.498(-4)$ \\
3 & 4 & 5 & 2 & 3 & 4 & 231321.9120 & $7.138(-4)$ \\
3 & 3 & 2 & 2 & 2 & 3 & 231321.9283 & $2.820(-6)$ \\
3 & 4 & 3 & 2 & 3 & 4 & 231321.9836 & $9.104(-7)$ \\
3 & 2 & 2 & 2 & 3 & 2 & 231321.9940 & $3.525(-7)$ \\
3 & 3 & 2 & 2 & 2 & 2 & 231322.1764 & $9.870(-5)$ \\
3 & 2 & 3 & 2 & 3 & 2 & 231322.3577 & $7.194(-9)$ \\
3 & 4 & 3 & 2 & 3 & 3 & 231322.3722 & $5.736(-5)$ \\
3 & 2 & 3 & 2 & 3 & 4 & 231322.4768 & $2.913(-6)$ \\
3 & 2 & 1 & 2 & 3 & 2 & 231322.4988 & $3.172(-6)$ \\
3 & 2 & 2 & 2 & 3 & 3 & 231322.5017 & $2.820(-6)$ \\
3 & 2 & 3 & 2 & 3 & 3 & 231322.8654 & $2.518(-7)$ \\
3 & 2 & 2 & 2 & 2 & 1 & 231323.9578 & $1.666(-5)$ \\
3 & 2 & 2 & 2 & 2 & 3 & 231324.0318 & $1.727(-5)$ \\
3 & 2 & 2 & 2 & 2 & 2 & 231324.2799 & $7.711(-5)$ \\
3 & 2 & 3 & 2 & 2 & 3 & 231324.3955 & $9.870(-5)$ \\
3 & 2 & 1 & 2 & 2 & 1 & 231324.4626 & $8.328(-5)$ \\
3 & 2 & 3 & 2 & 2 & 2 & 231324.6436 & $1.234(-5)$ \\
3 & 2 & 1 & 2 & 2 & 2 & 231324.7847 & $2.776(-5)$ \\
\hline
\end{tabular}

${ }^{a}$ The frequency uncertainty is $\pm 6.2 \mathrm{kHz}$ for all hyperfine components.

The corresponding correction with respect to $\mathrm{NH}_{3}(1,1)$ is

$(J: 1-0): 35.7 \mathrm{~m} \mathrm{~s}^{-1}$ or $-9.2( \pm 2.7) \mathrm{kHz}$

$(J: 2-1): 53.3 \mathrm{~m} \mathrm{~s}^{-1}$ or $-27( \pm 7.4) \mathrm{kHz}$

$(J: 3-2): 59.2 \mathrm{~m} \mathrm{~s}^{-1}$ or $-49( \pm 6.7) \mathrm{kHz}$.

Direct comparison of the reference position with $\mathrm{NH}_{3}(1,1)$ spectrum yields

(J: 1-0): $37.7 \mathrm{~m} \mathrm{~s}^{-1}\left(\sigma=0.85 \mathrm{~m} \mathrm{~s}^{-1}\right)$

(J: 2-1): $47.7 \mathrm{~m} \mathrm{~s}^{-1}\left(\sigma=0.92 \mathrm{~m} \mathrm{~s}^{-1}\right)$

$(J: 3-2): 63.6 \mathrm{~m} \mathrm{~s}^{-1}\left(\sigma=4.7 \mathrm{~m} \mathrm{~s}^{-1}\right)$.

\subsection{Rotational constants and Einstein-A coefficients}

Except for the $\mathrm{N}_{2} \mathrm{H}^{+}(J: 3-2)$ line, which has only one measurement, we used the averaged comparisons for correcting the frequencies of all these transitions.
Table 11. Hyperfine components and $A_{u l}$ Einstein spontaneous emission coefficients of the $(J: 4-3)$ transition of $\mathrm{N}_{2} \mathrm{D}^{+}$.

\begin{tabular}{|c|c|c|c|c|c|c|c|}
\hline$J^{\prime}$ & $F_{1}^{\prime}$ & $\overline{F^{\prime}}$ & $\rightarrow J$ & $\overline{F_{1}}$ & $\bar{F}$ & $\begin{array}{c}\text { Frequency }^{a} \\
\text { (MHz) }\end{array}$ & $\begin{array}{c}A_{u l} \\
\left(\mathrm{~s}^{-1}\right)\end{array}$ \\
\hline 4 & 4 & 4 & 3 & 4 & 3 & 308419.723 & $5.330(-6)$ \\
\hline 4 & 4 & 4 & 3 & 4 & 5 & 308419.794 & $5.361(-6)$ \\
\hline 4 & 4 & 3 & 3 & 4 & 3 & 308420.188 & $1.028(-4)$ \\
\hline 4 & 4 & 5 & 3 & 4 & 5 & 308420.218 & $1.053(-4)$ \\
\hline 4 & 4 & 4 & 3 & 4 & 4 & 308420.231 & $9.896(-5)$ \\
\hline 4 & 4 & 5 & 3 & 4 & 4 & 308420.655 & $4.386(-6)$ \\
\hline 4 & 4 & 3 & 3 & 4 & 4 & 308420.696 & $6.853(-6)$ \\
\hline 4 & 3 & 3 & 3 & 2 & 3 & 308421.627 & $1.790(-4)$ \\
\hline 4 & 5 & 5 & 3 & 4 & 5 & 308421.764 & $7.018(-5)$ \\
\hline 4 & 4 & 4 & 3 & 3 & 4 & 308421.765 & $1.028(-4)$ \\
\hline 4 & 3 & 3 & 3 & 2 & 2 & 308421.991 & $1.432(-3)$ \\
\hline 4 & 3 & 2 & 3 & 2 & 1 & 308421.993 & $1.353(-3)$ \\
\hline 4 & 3 & 4 & 3 & 2 & 3 & 308422.056 & $1.611(-3)$ \\
\hline 4 & 3 & 3 & 3 & 4 & 3 & 308422.120 & $1.399(-7)$ \\
\hline 4 & 4 & 4 & 3 & 3 & 3 & 308422.132 & $1.542(-3)$ \\
\hline 4 & 3 & 2 & 3 & 2 & 3 & 308422.134 & $7.161(-6)$ \\
\hline 4 & 4 & 3 & 3 & 3 & 2 & 308422.162 & $1.511(-3)$ \\
\hline 4 & 4 & 5 & 3 & 3 & 4 & 308422.189 & $1.645(-3)$ \\
\hline 4 & 5 & 4 & 3 & 4 & 3 & 308422.195 & $1.668(-3)$ \\
\hline 4 & 5 & 5 & 3 & 4 & 4 & 308422.200 & $1.684(-3)$ \\
\hline 4 & 5 & 6 & 3 & 4 & 5 & 308422.230 & $1.754(-3)$ \\
\hline 4 & 4 & 3 & 3 & 3 & 4 & 308422.231 & $2.098(-6)$ \\
\hline 4 & 5 & 4 & 3 & 4 & 5 & 308422.266 & $8.664(-7)$ \\
\hline 4 & 3 & 2 & 3 & 2 & 2 & 308422.498 & $2.506(-4)$ \\
\hline 4 & 3 & 4 & 3 & 4 & 3 & 308422.549 & $1.727(-9)$ \\
\hline 4 & 4 & 3 & 3 & 3 & 3 & 308422.598 & $1.322(-4)$ \\
\hline 4 & 3 & 4 & 3 & 4 & 5 & 308422.621 & $2.127(-6)$ \\
\hline 4 & 3 & 2 & 3 & 4 & 3 & 308422.628 & $2.238(-6)$ \\
\hline 4 & 3 & 3 & 3 & 4 & 4 & 308422.628 & $2.098(-6)$ \\
\hline 4 & 5 & 4 & 3 & 4 & 4 & 308422.703 & $8.577(-5)$ \\
\hline 4 & 3 & 4 & 3 & 4 & 4 & 308423.057 & $1.088(-7)$ \\
\hline 4 & 3 & 3 & 3 & 3 & 2 & 308424.094 & $1.119(-5)$ \\
\hline 4 & 3 & 3 & 3 & 3 & 4 & 308424.163 & $1.133(-5)$ \\
\hline 4 & 3 & 3 & 3 & 3 & 3 & 308424.530 & $1.185(-4)$ \\
\hline 4 & 3 & 4 & 3 & 3 & 4 & 308424.592 & $1.322(-4)$ \\
\hline 4 & 3 & 2 & 3 & 3 & 2 & 308424.602 & $1.253(-4)$ \\
\hline 4 & 3 & 4 & 3 & 3 & 3 & 308424.959 & $8.812(-6)$ \\
\hline 4 & 3 & 2 & 3 & 3 & 3 & 308425.037 & $1.567(-5)$ \\
\hline
\end{tabular}

${ }^{a}$ The frequency uncertainty is $\pm 25 \mathrm{kHz}$ for all hyperfine components.

From these new frequencies, we derived the rotation (B) and centrifugal distortion (D) constants for $\mathrm{N}_{2} \mathrm{H}^{+}$and $\mathrm{N}_{2} \mathrm{D}^{+}$, using the hyperfine constants given by Caselli et al. (1995) and Dore et al. (2004), respectively. The error budget was estimated by adding $1 \sigma$ to one of the frequency measurements and subtracting $1 \sigma$ to the other, which we used to determine $\mathrm{B}$ and $\mathrm{D}$, e.g. $+2.7 \mathrm{kHz}$ to the $\mathrm{N}_{2} \mathrm{D}^{+}(\mathrm{J}: 1-0)$ line and $-6.7 \mathrm{kHz}$ for the $\mathrm{N}_{2} \mathrm{D}^{+}$ $(J: 3-2)$ line. For the $\mathrm{N}_{2} \mathrm{H}^{+}(J: 3-2)$ transition, as we have only one measurement, we took the average of the $1 \sigma$ dispersion for all the other transition measurements as a probable dispersion for that measurement if we had had as many observations. We found an average velocity dispersion of $11.5 \mathrm{~m} \mathrm{~s}^{-1}$, which corresponds to $10.7 \mathrm{kHz}$ at that frequency. The new constants are listed in Table 1. As expected from Amano et al. (2005) making use of the Caselli et al. (1995) frequency determination of $\mathrm{N}_{2} \mathrm{H}^{+}$and the related Dore et al. (2004) $\mathrm{N}_{2} \mathrm{D}^{+}$measurements, their rotational constants are different from ours by an amount directly related to the difference between $\mathrm{C}_{3} \mathrm{H}_{2}$ and $\mathrm{NH}_{3}$ velocity 
Table 12. Hyperfine components and $A_{u l}$ Einstein spontaneous emission coefficients of the $(J: 5-4)$ transition of $\mathrm{N}_{2} \mathrm{D}^{+}$.

\begin{tabular}{|c|c|c|c|c|c|c|c|}
\hline$J^{\prime}$ & $\overline{F_{1}^{\prime}}$ & $F^{\prime}$ & & $\overline{F_{1}}$ & $\bar{F}$ & $\begin{array}{c}\text { Frequency }^{a} \\
(\mathrm{MHz})\end{array}$ & $\begin{array}{c}A_{u l} \\
\left(\mathrm{~s}^{-1}\right)\end{array}$ \\
\hline 5 & 5 & 5 & 4 & 5 & 4 & 385514.088 & $4.587(-6)$ \\
\hline 5 & 5 & 5 & 4 & 5 & 6 & 385514.125 & $4.601(-6)$ \\
\hline 5 & 5 & 4 & 4 & 5 & 4 & 385514.562 & $1.346(-4)$ \\
\hline 5 & 5 & 6 & 4 & 5 & 6 & 385514.584 & $1.363(-4)$ \\
\hline 5 & 5 & 5 & 4 & 5 & 5 & 385514.591 & $1.310(-4)$ \\
\hline 5 & 5 & 6 & 4 & 5 & 5 & 385515.050 & $3.894(-6)$ \\
\hline 5 & 5 & 4 & 4 & 5 & 5 & 385515.065 & $5.607(-6)$ \\
\hline 5 & 4 & 4 & 4 & 3 & 4 & 385 & $2.082(-4)$ \\
\hline 5 & 5 & 5 & 4 & 4 & 5 & 385 & $1.346(-4)$ \\
\hline 5 & 6 & 6 & 4 & 5 & 6 & & .734( \\
\hline 5 & 4 & 4 & 4 & 5 & 4 & 385 & 6.922 \\
\hline 5 & 4 & 3 & 4 & 3 & 2 & 385 & 3.059 \\
\hline 5 & 4 & 4 & 4 & 3 & 3 & 385 & 3.123( \\
\hline 5 & 4 & 5 & 4 & 3 & 4 & 385516.516 & $3.331(-3)$ \\
\hline 5 & 4 & 3 & 4 & 3 & 4 & 385516.553 & $4.249(-6)$ \\
\hline 5 & 5 & 5 & 4 & 4 & 4 & 385516 & $3.230(-3)$ \\
\hline 5 & 5 & 4 & 4 & 4 & 3 & 38551 & $3.198(-3)$ \\
\hline 5 & 5 & 6 & 4 & 4 & 5 & 385 & $3.364(-3)$ \\
\hline 5 & 6 & 5 & 4 & 5 & 4 & 385 & 3.388( \\
\hline 5 & 6 & 6 & 4 & 5 & 5 & & $3.407(-3)$ \\
\hline 5 & 5 & 4 & 4 & 4 & 5 & & $1.661(-6)$ \\
\hline 5 & 6 & 7 & 4 & 5 & 6 & & 3.504 \\
\hline 5 & 6 & 5 & 4 & 5 & 6 & 385 & 8.045 \\
\hline 5 & 4 & 5 & 4 & 5 & 4 & 385 & $5.721 e$ \\
\hline 5 & 4 & 3 & 4 & 5 & 4 & 385 & 1.731 \\
\hline 5 & 4 & 5 & 4 & 5 & 6 & 385 & 1.673 ( \\
\hline 5 & 4 & 4 & 4 & 5 & 5 & 3855 & $1.661(-6)$ \\
\hline 5 & 4 & 3 & 4 & 3 & 3 & 385516.982 & $2.677(-4)$ \\
\hline 5 & 5 & 4 & 4 & 4 & 4 & 385517.034 & $1.645(-4)$ \\
\hline 5 & 6 & 5 & 4 & 5 & 5 & 3855 & $1.150(-4)$ \\
\hline 5 & 4 & 5 & 4 & 5 & 5 & 385517.373 & $5.663(-8)$ \\
\hline 5 & 4 & 4 & 4 & 4 & 3 & 3855 & $8.328(-6)$ \\
\hline 5 & 4 & 4 & 4 & 4 & 5 & 385518.4 & $8.376(-6)$ \\
\hline 5 & 4 & 4 & 4 & 4 & 4 & 3855 & $1.546(-4)$ \\
\hline 5 & 4 & 3 & 4 & 4 & 3 & 385518.914 & $1.606(-4)$ \\
\hline 5 & 4 & 5 & 4 & 4 & 5 & 385518.919 & $1.645(-4)$ \\
\hline 5 & 4 & 5 & 4 & 4 & 4 & 385519.343 & $6.853(-6)$ \\
\hline 5 & 4 & 3 & 4 & 4 & 4 & 385519.379 & $1.071(-5)$ \\
\hline
\end{tabular}

${ }^{a}$ The frequency uncertainty is $\pm 58 \mathrm{kHz}$ for all hyperfine components.

determinations. The difference $\left(5.3 \mathrm{kHz}\right.$ for $\mathrm{B}\left(\mathrm{N}_{2} \mathrm{H}^{+}\right)$and $9.2 \mathrm{kHz}$ for $\left.\mathrm{B}\left(\mathrm{N}_{2} \mathrm{D}^{+}\right)\right)$is significantly greater than the error estimate (conservatively given to be 2.5 and $1.7 \mathrm{kHz}$ for us and 1.3 and $1.2 \mathrm{kHz}$ for Amano et al. 2005). It would be interesting to repeat the Amano et al. (2005) analysis with our new frequency determinations to secure these values better.

Line strengths, from which Einstein- $A$ coefficients are defined, are determined from the reduced transition matrix elements of the dipole moment operator:

$S(1 \rightarrow 2)=\left|\left\langle\psi_{1}\|\hat{d}\| \psi_{2}\right\rangle\right|^{2}$

where $\mid \psi_{1}>$ and $\mid \psi_{2}>$ are the wave-functions of the two levels involved in the radiative transition. In the case of hyperfine structures, the wave-functions can be defined according to an expansion on Hund's case (b) wave-functions, the coefficients being determined by diagonalization of the hyperfine Hamiltonian. In the case of $\mathrm{N}_{2} \mathrm{H}^{+}$and $\mathrm{N}_{2} \mathrm{D}^{+}$, the mixing of states is low so that
Table 13. Hyperfine components and $A_{u l}$ Einstein spontaneous emission coefficients of the $(J: 6-5)$ transition of $\mathrm{N}_{2} \mathrm{D}^{+}$.

\begin{tabular}{|c|c|c|c|c|c|c|c|}
\hline$J^{\prime}$ & $F_{1}^{\prime}$ & $\bar{F}$ & $\rightarrow J$ & $\overline{F_{1}}$ & $\bar{F}$ & $\begin{array}{c}\text { Frequency }^{a} \\
(\mathrm{MHz})\end{array}$ & $\begin{array}{c}A_{u l} \\
\left(\mathrm{~s}^{-1}\right)\end{array}$ \\
\hline 6 & 6 & 6 & 5 & 6 & 5 & 462601.05 & $4.014(-6)$ \\
\hline 6 & 6 & 6 & 5 & 6 & 7 & 462601.06 & $4.021(-6)$ \\
\hline 6 & 6 & 5 & 5 & 6 & 5 & 462601.53 & $1.660(-4)$ \\
\hline 6 & 6 & 7 & 5 & 6 & 7 & 462601.54 & $1.673(-4)$ \\
\hline 6 & 6 & 6 & 5 & 6 & 6 & 462601.55 & $1.627(-4)$ \\
\hline 6 & 6 & 5 & 5 & 6 & 6 & 462602.02 & $4.744(-6)$ \\
\hline 6 & 6 & 7 & 5 & 6 & 6 & 462602.03 & $3.485(-6)$ \\
\hline 6 & 5 & 5 & 5 & 4 & 5 & 462603.04 & $2.378(-4)$ \\
\hline 6 & 6 & 6 & 5 & 5 & 6 & 462603.10 & $1.660(-4)$ \\
\hline 6 & 7 & 7 & 5 & 6 & 7 & 462603.11 & $1.255(-4)$ \\
\hline 6 & 5 & 5 & 5 & 6 & 5 & 462603.32 & $3.920(-8)$ \\
\hline 6 & 5 & 4 & 5 & 4 & 3 & 462603.50 & $5.651(-3)$ \\
\hline 6 & 5 & 5 & 5 & 4 & 4 & 462603.51 & $5.707(-3)$ \\
\hline 6 & 5 & 6 & 5 & 4 & 5 & 462603.53 & $5.945(-3)$ \\
\hline 6 & 5 & 4 & 5 & 4 & 5 & 462603.54 & $2.936(-6)$ \\
\hline 6 & 6 & 5 & 5 & 5 & 4 & 462603.56 & $5.780(-3)$ \\
\hline 6 & 6 & 6 & 5 & 5 & 5 & 462603.56 & $5.811(-3)$ \\
\hline 6 & 6 & 5 & 5 & 5 & 6 & 462603.58 & $1.372(-6)$ \\
\hline 6 & 6 & 7 & 5 & 5 & 6 & 462603.59 & $5.977(-3)$ \\
\hline 6 & 7 & 6 & 5 & 6 & 5 & 462603.59 & $6.002(-3)$ \\
\hline 6 & 7 & 7 & 5 & 6 & 6 & 462603.60 & $6.022(-3)$ \\
\hline 6 & 7 & 6 & 5 & 6 & 7 & 462603.60 & $7.424(-7)$ \\
\hline 6 & 7 & 8 & 5 & 6 & 7 & 462603.61 & $6.148(-3)$ \\
\hline 6 & 5 & 6 & 5 & 6 & 5 & 462603.81 & $2.320 e-10$ \\
\hline 6 & 5 & 4 & 5 & 6 & 5 & 462603.81 & $1.411(-6)$ \\
\hline 6 & 5 & 5 & 5 & 6 & 6 & 462603.81 & $1.372(-6)$ \\
\hline 6 & 5 & 6 & 5 & 6 & 7 & 462603.81 & $1.378(-6)$ \\
\hline 6 & 5 & 4 & 5 & 4 & 4 & 462604.00 & $2.906(-4)$ \\
\hline 6 & 6 & 5 & 5 & 5 & 5 & 462604.04 & $1.962(-4)$ \\
\hline 6 & 7 & 6 & 5 & 6 & 6 & 462604.09 & $1.448(-4)$ \\
\hline 6 & 5 & 6 & 5 & 6 & 6 & 462604.30 & $3.317(-8)$ \\
\hline 6 & 5 & 5 & 5 & 5 & 4 & 462605.35 & $6.605(-6)$ \\
\hline 6 & 5 & 5 & 5 & 5 & 6 & 462605.37 & $6.626(-6)$ \\
\hline 6 & 5 & 5 & 5 & 5 & 5 & 462605.83 & $1.886(-4)$ \\
\hline 6 & 5 & 4 & 5 & 5 & 4 & 462605.85 & $1.938(-4)$ \\
\hline 6 & 5 & 6 & 5 & 5 & 6 & 462605.86 & $1.962(-4)$ \\
\hline 6 & 5 & 6 & 5 & 5 & 5 & 462606.32 & $5.606(-6)$ \\
\hline 6 & 5 & 4 & 5 & 5 & 5 & 462606.32 & $8.073(-6)$ \\
\hline
\end{tabular}

a The frequency uncertainty is $\pm 0.11 \mathrm{MHz}$ for all hyperfine components.

a given hyperfine wave-function can be accurately defined as a pure Hund's case (b) wave-function. Doing so, the line strengths can be expressed in a closed form (Gordy \& Cook 1984) and, for $\mathrm{N}_{2} \mathrm{H}^{+}$, the relevant expressions being given in Daniel et al. (2006). The Einstein- $A$ coefficients are then given by

$A_{J F_{1} F \rightarrow J^{\prime} F_{1}^{\prime} F^{\prime}}=\frac{64 \pi^{4}}{3 h c^{3}} \mu^{2} v_{J F_{1} F \rightarrow J^{\prime} F_{1}^{\prime} F^{\prime}}^{3} \times \frac{J}{[F]} s_{J F_{1} F \rightarrow J^{\prime} F_{1}^{\prime} F^{\prime}}$

(This is the same equation as in Daniel et al. 2006, but corrected for two typographical errors).

The calculated line frequencies and $A_{u l}$ coefficients (the dipole moment $-\mu=3.37 \mathrm{D}-$ is taken from Botschwina 1984) are given in Tables 2 to 10 for all rotational transitions from $(J: 1-0)$ to $(J: 6-5)$ for both $\mathrm{N}_{2} \mathrm{H}^{+}$and $\mathrm{N}_{2} \mathrm{D}^{+}$. The frequency uncertainty is estimated by varying the rotational $\mathrm{B}$ and $\mathrm{D}$ constants by $\pm 1 \sigma$. 


\section{Conclusions}

New, more accurate rotational constants and line frequencies are given along with the detailed Einstein spontaneous coefficients $\left(A_{u l}\right)$ for each of the hyperfine components. The main prestellar core LSR velocity is $2.3670( \pm 0.0004) \mathrm{km} \mathrm{s}^{-1}$.

Acknowledgements. We thank an anonymous referee for her/his critical reading that helped to improve the manuscript.

\section{References}

Amano, T., Hirao, T., \& Takano, J. 2005, J. Mol. Spectro., 234, 170 Botschwina, P. 1984, Chem. Phys. Lett., 107, 535

Caselli, P., Myers, P. C., \& Thaddeus, P. 1995, ApJ, 455, L77

Crapsi, A., Caselli, P., Walmsley, C. M., et al. 2005, ApJ, 619, 379

Daniel, F., Cernicharo, J., \& Dubernet, M.-L. 2006, ApJ, 648, 461

Dore, L., Caselli, P., Beninati, S., et al. 2004, A\&A, 413, 1177
Gerin, M., Pearson, J. C., Roueff, E., Falgarone, E., \& Phillips, T. G. 2001, ApJ, 551, L193

Gordy, W., \& Cook, R. L. 1984, Microwave molecular spectra Techniques of chemistry, 18

Hougen, J. T. 1972, J. Chem. Phys., 57, 4207

Kuiper, T. B. H., Langer, W. D., \& Velusamy, T. 1996, ApJ, 468, 761

Kukolich, S. G. 1967, Phys. Rev., 156, 83

Lee, C. W., Myers, P. C., \& Tafalla, M. 1999, ApJ, 526, 788

Pagani, L., Gallego, A. T., \& Apponi, A. J. 2001, A\&A, 380, 384

Pagani, L., Gallego, A. T., \& Apponi, A. J. 2002, A\&A, 381, 1094 (Erratum)

Pagani, L., Bacmann, A., Motte, F., et al. 2004, A\&A, 417, 605

Pagani, L., Pardo, J.-R., Apponi, A. J., Bacmann, A., \& Cabrit, S. 2005, A\&A, 429,181

Pagani, L., Bacmann, A., Cabrit, S., \& Vastel, C. 2007, A\&A, 467, 179

Roberts, H., \& Millar, T. J. 2007, A\&A, 471, 849

Schmid-Burgk, J., Muders, D., Müller, H. S. P., \& Brupbacher-Gatehouse, B. 2004, A\&A, 419, 949

Swade, D. A. 1989, ApJS, 71, 219

Tafalla, M., Myers, P. C., Caselli, P., Walmsley, C. M., \& Comito, C. 2002, ApJ, 569,815

Tafalla, M., Myers, P. C., Caselli, P., \& Walmsley, C. M. 2004, A\&A, 416, 191

Willacy, K., Langer, W. D., \& Velusamy, T. 1998, ApJ, 507, L171 